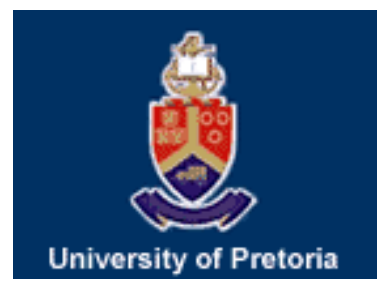

University of Pretoria

Department of Economics Working Paper Series

The Sensitivity of the South African Industrial Sector's Electricity Consumption to Electricity Price Fluctuations

Roula Inglesi-Lotz

University of Pretoria

Working Paper: 2012-25

August 2012

Department of Economics

University of Pretoria

0002, Pretoria

South Africa

Tel: +27 124202413 


\title{
The sensitivity of the South African industrial sector's electricity consumption to electricity price fluctuations
}

\author{
Roula Inglesi-Lotz ${ }^{1}$
}

\begin{abstract}
Numerous studies have assumed that the price elasticity of electricity demand remains constant through the years that is industrial consumers behave the same way to price fluctuations regardless the actual price level. This paper proposes that the price elasticity of industrial electricity demand is time varying. To do so, the Kalman filter methodology is employed in an effort to provide the policy makers with more information on the behaviour of the industrial sector with regards to electricity price changes, focusing on the period from 1970 to 2007. To capture other factors affecting electricity consumption, such as real output and employment are also included in the specification. The findings show that price sensitivity changed since the 1970s: it has decreased in absolute values from -1 in 1980 to -0.953 in 1990 and then stabilised at around -0.95 showing that the industrial sector has experienced an inelastic demand. In other words, the behaviour of the industrial consumers did not vary significantly in the 2000s. In the long run and as the prices increase, probably reaching the levels of the 1970s or even before, the industrial sector's behaviour might change and the elasticity might end up at levels higher than one (elastic).
\end{abstract}

Keywords: electricity consumption; Kalman filter; price elasticity; industrial sector

\footnotetext{
${ }^{1}$ Department of Economics, University of Pretoria. Email: roula.inglesi-lotz@up.ac.za. Telephone: +27 12420 4504
} 


\section{Introduction}

In South Africa, choosing the correct and appropriate electricity price regime has been an issue for discussion during the last decade. Recently (March 2012), the National Energy Regulator South Africa (NERSA) re-evaluated and reduced the agreed rate of increase of electricity price for 2012. Eskom has also expressed its intentions for further application on price rises for two main reasons. Firstly Eskom argues that the current prices are not cost-reflective. Additionally, the capacity expansion plans of the utility include the investing in two new power plants that will increase the company's operating costs in the future. Before the next electricity price restructure, it is imperative for the policy makers to be able to understand and in a way, "predict" the reactions of consumers to price changes. Even more important, the national electricity consumption trends do not necessarily represent each sector's behaviour individually. Different price structures as well as different electricity profiles are the main reasons why different economic sectors should be examined separately and treated accordingly.

Energy (and more specifically electricity) plays an essential role in the production capacity of a country and a crucial one for specifically the manufacturing sector where energy is considered an irreplaceable input. In South Africa, the industrial sector is responsible for an average of approximately $58 \%$ of the total electricity consumption, making this sector one of the most important ones from an energy consumption point of view. Ziramba (2009) studied the energy consumption of the industrial sector in South Africa and its interaction with other variables such as industrial output and employment (but not electricity prices). More recently, Inglesi-Lotz and Blignaut (2011) found out that among various economic sectors such as agriculture and transport, the industrial sector was the only one whose electricity consumption behaviour was found sensitive to price fluctuations on average during the period 1993 to 2006.

Following Inglesi-Lotz (2011), this paper proposes that the sensitivity of the industrial sector's electricity consumption to price fluctuations (price elasticity) has been changing through the years. As Inglesi-Lotz (2011) also points out "focus on variation is more important than only examining the level of change" especially for the South African case after the price restructuring of 2009/10. The fluctuations are so drastic that one has to take into account changes in behaviour. Thus, the purpose of this paper is to estimate the time-varying sensitivity of the industrial sector's electricity consumption to price changes by using the Kalman filter econometric methodology for the period 1970 to 2007 (see section on data for a discussion on the reasons for the selection of the time period).

All in all, this paper will combine and extend the results by Inglesi-Lotz (2011) and InglesiLotz and Blignaut (2011a) in an effort to provide the policy makers with more information on the behaviour of the industrial sector with regards to electricity price changes. The findings will assist the regulators and policy makers with future decisions on price changes, topic extremely relevant and crucial for the South African case recently.

The paper continues as follows: Section 2 provides a brief review of studies that dealt with the industrial sector's energy or electricity consumption, as well as a summary of the South African studies that dealt with electricity prices and their effect to the economy in its entirety or looking only at specific sectors. The following section presents the methodology used and the data employed, while next the empirical results are presented. Finally the last section summarises the findings and concludes by discussing some possible policy implications. 


\section{Literature review}

In the last decades, a special attention on price elasticities of energy demand has emerged in the literature. A possible reason for this is the concerns for the environmental effects of the rising energy demand internationally and the even increasing need to find appropriate instruments (if existing) to control it. The industrial sector specifically attracted more attention since currently it consumes about $37 \%$ of the world's total delivered energy (Abdelaziz et al., 2011).

Many studies have been conducted on energy (electricity) demand of the industrial sector looking at a variety of countries within different geographical regions and with different economic backgrounds. Also, numerous econometric and other methods were employed. In addition, different variables were used as other factors affecting the demand except for prices depending on the specific region and the time period but all in all, the major determinants of the industrial sector's energy (electricity) demand in the majority of the studies are output, price of electricity and employment (Al-Ghandoor et al. 2008; Jamil and Ahmad, 2011).

Table 1: Summary of selected international and local studies on price elasticity of energy (electricity) demand in the industrial sector

\begin{tabular}{|c|c|c|c|c|}
\hline Authors & Year & Country/region & Sector & Price elasticity \\
\hline Pindcyck & 1979 & Group of countries & Industrial \& Commercial & -0.07 to -0.16 \\
\hline Lynk & 1989 & UK & Industrial & -0.69 \\
\hline Caloghirou et al. & 1997 & Greece & Industrial & -0.90 \\
\hline Beenstock et al. & 1999 & Israel & Industrial & 0.123 \\
\hline Hunt et al. & 2003 & UK & Manufacturing & $\begin{array}{c}-0.20 \\
\text { or } 0.16 \text { to } 0.323\end{array}$ \\
\hline Kamerchen, Porter & 2004 & Oman & Industrial & -0.34 to -0.55 \\
\hline Dimitropoulos et al. & 2005 & UK & Manufacturing & -0.159 \\
\hline Roy et al. & 2006 & Country panel & Industrial & -0.80 to -1.76 \\
\hline Enevoldsen et al. & 2007 & $\begin{array}{c}\text { Denmark, Norway } \\
\text { and Sweden }\end{array}$ & Industrial & -0.35 to -0.44 \\
\hline Agnolucci & 2007 & UK & Industrial & -0.60 \\
\hline Agnolucci & 2009 & UK and Germany & Industrial & -0.64 \\
\hline Inglesi-Lotz and Blignaut & 2011 & South Africa & Industrial & -0.869 \\
\hline He et al. & 2011 & China & Industrial \& Commercial & -0.018 \\
\hline
\end{tabular}

In Table 1, a summary of international and local studies and their findings (in chronological order) that dealt with the industrial energy (electricity) demand is presented. This group of studies, although by no means exhaustive of the literature, is indicative of the literature's focus on a variety of countries (developed and developing) for different time periods. A variety of numerical estimations of the price elasticity is also observed depending on the country and more importantly the period of the sample.

For South Africa, only one study was identified that shed some light on the reaction of the industrial sector (among others) to the changes of prices (Inglesi-Lotz and Blignaut, 2011a). Ziramba (2009) also studied the industrial sector's electricity demand reactions but excluded the price from the factors affecting it. Another recent study by Inglesi-Lotz and Blignaut (2011b) looked at the 
different economic sectors and the factors that affected their increasing electricity consumption but due to the nature of the method employed (decomposition techniques) the effects of price fluctuations were not studied. Other studies also looked at the trends in electricity demand trends in South Africa (Inglesi, 2010; Odhiambo, 2009; Amusa et al., 2010; Inglesi-Lotz, 2011) but focused on the aggregate demand of the economy. Also, Ziramba (2008) found that price was an insignificant factor for the residential demand of electricity in South Africa for the period 1978-2005. 


\section{Methodology and Data}

\subsection{Econometric method}

Econometric methods used in the analysis of energy vary in complexity from simple to relatively complicated and have been applied to data of temporal, spatial and sectoral detail (Greening et al., 2007). More specifically, co-integration techniques (Engle and Granger, 1987; Johansen, 1991, Hendy and Juselius, 2000; Hendry and Juselius, 2001) have been used internationally and locally (Inglesi, 2010) to estimate the determinants of energy and electricity consumption. However, the common constraint to all this type of studies is the assumption that the relationship between the electricity prices and consumption has remained constant through the years. Hence, to take this a step further, Inglesi-Lotz (2011) has employed the Kalman filter technique proposing that the price elasticity evolved during the years and should not be treated as stable. So, with this method, it is not assumed that there is an average elasticity through the years and it can be shown that the electricity consumers might behave differently under various price regimes and during various time periods.

Slade (1989) proposes the Kalman filter as a paradigmatic framework to estimate regressions with time-varying parameters. As Morisson and Pike (1977) also explain that in the case that the estimated coefficients do not vary over time, the Kalman filter's results should not differ substantially to those of a least squares estimation. However, they continue to stress that the Kalman filter results are proven superior in the case of parameter instability. Hence, it is of importance to test for the general stability of parameters before selecting Kalman filter as the method of preference. To test for instability of parameters, Hansen (1992) proposes a version of past approaches to cover general models with stochastic and deterministic trends. Hence, in this paper, this test is used to confirm or reject statistically the assumption of time-varying price elasticity before proceeding with the estimation.

There are two main types of models in compliance to representation via Kalman filter: a) unobservable components models and b) time-varying parameter models (Cuthbertson et al. 1992). In this study, the state-space model is applied with stochastically time-varying parameters to a linear regression in which coefficients representing elasticities are allowed to change over time.

Firstly ${ }^{2}$, the formal representation of a dynamic system written in state-space form suitable for the Kalman filter should be described. The following system of equations presents the statespace model of the dynamics of a $\mathrm{n} x 1$ vector, $\mathrm{y}_{\mathrm{t}}$.

Observation (or measurement) equation: $y_{t}=A x_{t}+H \xi_{t}+w_{t}$

State (or transition) equation: $\xi_{t+1}=F \xi_{t}+v_{t+1}$

where $A, H$ and $F$ are matrices of parameters of dimension $(n x k),(n x r),(r \times r)$, respectively, and $x_{t}$ is a $(k \times 1)$ vector of exogenous or predetermined variables. $\xi_{t}$ is a $(r \times 1)$ vector of possibly unobserved state variables, known as the state vector.

\footnotetext{
${ }^{2}$ The detailed discussion on the Kalman filter methodology is adopted directly from Inglesi-Lotz (2011).
} 
The following two equations represent the characteristics of the disturbance vectors wt and vt which are assumed to be independent white noise.

$$
\begin{aligned}
& E\left(v_{t} v_{\tau}^{\prime}\right)=\left\{\begin{array}{l}
Q, \text { for } t=\tau \\
0, \text { otherwise }
\end{array}\right. \\
& E\left(w_{t} w_{\tau}^{\prime}\right)=\left\{\begin{array}{l}
R, \text { for } t=\tau \\
0, \text { otherwise }
\end{array}\right.
\end{aligned}
$$

where $Q$ and $R$ are $(r \times r)$ and $(n \times n)$ matrices, respectively.

As shown in the following two equations, the disturbances $v_{t}$ and $w_{t}$ are uncorrelated at all lags.

$E\left(v_{t} w_{\tau}^{\prime}\right)=0$ for all $t$ and $\tau$

In the observation equation the factor $x_{t}$ is considered to be predetermined or exogenous which does not provide information about $\xi_{t+s}$ or $w_{t+s}$ for $s=0,1,2, \ldots$ beyond what is given by the sequence $\mathrm{y}_{\mathrm{t}-1}, \mathrm{y}_{\mathrm{t}-2}, \ldots, \mathrm{y}_{1}$. Thus, $\mathrm{x}_{\mathrm{t}}$ could include lagged values of $\mathrm{y}$ or variables which are uncorrelated with $\xi_{\tau}$ and $\mathrm{w}_{\tau}$ for all $\tau$.

The overall system of equations is used to explain a finite series of observations $\left\{y_{1}, y_{2}, \ldots, y_{T}\right\}$ for which assumptions about the initial value of the state vector $\xi$ are needed. With the assumption that the parameter matrices $(F, Q, A, H$ or $R)$ are functions of time, then the state-space representation (equations (1) and (2)) become:

$y_{t}=a\left(x_{t}\right)+\left[H\left(x_{t}\right)\right]^{\prime} \xi_{t}+w_{t}$

$\xi_{t+1}=F\left(x_{t}\right) \xi_{t}+v_{t+1}$

Where $F(x t)$ is a $(r \times r)$ matrix whose elements are functions of $x_{t} ; \alpha\left(x_{t}\right)$ is a $(n \times 1)$ vector-valued function; and $H\left(x_{t}\right)$ is a $(r \times n)$ matrix -valued function.

Equations (6) and (7) allow for stochastically varying parameters, but are is more restrictive in the sense that a Gaussian distribution is assumed.

With regards to the specific application to the electricity model of this paper, the dependent variable is the electricity consumption of the industrial sector (cons) while standard variables used in the international and local literature (Ziramba, 2009; Inglesi, 2010; Nakajima and Hamori, 2010; Dilaver and Hunt,2010) are considered as independent: price of electricity ( $p)$, real output of the industrial sector ( $\mathrm{y}$ ) and employment ( $\mathrm{n}$ ). All the variables are in natural log denoted by I.

lcons $=a_{0}+a_{1} l p+a_{2} l y+a_{3} l n+\varepsilon_{t}$ 
In equation (8) all the parameters $\alpha$ are considered constant over time. However, after using the Hansen (1992) test, they will be identified as time-varying or remain constant. An indication of this will be given even before the statistical test by the graphical representation of the data. The timevarying parameters will then also have a suffix $t$ to denote the fluctuations over time to be estimated.

\section{$3.2 \quad$ Data}

Primarily local sources of data were used for this exercise. Average electricity consumption is derived from different sources: South African Energy Statistics by the National Energy Council (NEC, 1990) for the years from 1970 to 1989 and the Energy Balances by the Department of Energy (DoE, various issues). The series for average nominal prices of electricity for the industrial sector is obtained by the Energy Price report also by the Department of Energy (DoE, 2009). Finally, the data series for the real economic output and employment of the industrial sector is obtained from the Quantec databases (Quantec, n.d.). The economic output figures are presented in real terms with 2005 being the base year. In order to transform, the nominal prices of electricity into constant with 2005 base year, the Consumer Price Index (CPI) figures from StatsSA is employed.

The electricity consumption was measured in $\mathrm{kWh}$; the electricity prices (after the transformation) in South African Rand (ZAR) cents/ kWh (constant prices 2005); the economic output of the industrial sector in ZAR (constant prices 2005) and the employment in absolute number of employees.

Table 2: Data descriptive statistics

\begin{tabular}{ccccc}
\hline Variable & $\begin{array}{c}\text { Electricity consumption of } \\
\text { the industrial sector }\end{array}$ & $\begin{array}{c}\text { Average Electricity } \\
\text { price of industrial } \\
\text { sector }\end{array}$ & $\begin{array}{c}\text { Real economic output } \\
\text { of industrial sector }\end{array}$ & $\begin{array}{c}\text { Employment of the } \\
\text { industrial sector }\end{array}$ \\
\hline $\begin{array}{c}\text { Unit of } \\
\text { measurement }\end{array}$ & $\begin{array}{c}\text { kWh } \\
\text { (in natural log) }\end{array}$ & $\begin{array}{c}\text { ZAR cents per kWh } \\
\text { (in natural log) }\end{array}$ & $\begin{array}{c}\text { ZAR } \\
\text { (in natural log) }\end{array}$ & $\begin{array}{c}\text { Number } \\
\text { (in natural log) }\end{array}$ \\
\hline Mean & 24.38 & 2.92 & 34.20 & 14.64 \\
Median & 24.46 & 2.85 & 34.18 & 14.69 \\
Maximum & 25.34 & 3.28 & 34.86 & 14.81 \\
Minimum & 23.16 & 2.61 & 33.64 & 14.21 \\
Std. Dev. & 0.59 & 0.22 & 0.33 & 0.15 \\
Skewness & -0.31 & 0.21 & 0.29 & -1.17 \\
Kurtosis & 2.22 & 1.60 & 2.41 & 3.60 \\
Jarque-Bera & 1.55 & 3.41 & 1.10 & 9.20 \\
Probability & 0.46 & 0.18 & 0.58 & 0.01 \\
Sum & 926.36 & 110.83 & 1299.68 & 556.28 \\
Sum Sq. Dev. & 12.91 & 1.86 & 3.91 & 0.88 \\
Observations & 38 & 38 & 38 & 38 \\
\hline
\end{tabular}

[Source: DoE (various issues), DoE (2009), Quantec (n.d.)] 
Table 2 summarises the descriptive statistics of all the variables (in their linearised version) used in the analysis. These primary statistics are presented only as an indication of the nature of the raw data.

Figure 1 illustrates the data of electricity consumption and prices as well as the real economic output and employment of the South African industrial sector for the period 1970 until 2008. It can be seen that the industrial economic output and its electricity consumption showed an upward trend for the whole period examined. This trend became more intense since the 1990s that the sanctions were lifted and the country's trade opened to the rest of the world. Since then the real economic production of the country rose with increasing rates that match the rising electricity consumption of the sector.

Employment showed a general upward trend until the end of 1980s approximately and then its variation relatively stabilised until the end of the sample. This can be attributed to the industrialisation of the economy. One can argue that the growth of the sector during this period led to substitution of labour to capital especially after the opening to international markets and the opportunities to import capital infrastructure and know-how. Although this fact was indeed a reality, the labour market opened to all previously disadvantaged South Africans and hence, more employment opportunities were available. The lower labour costs of unskilled or semiskilled workers also played a role in the higher number of labour employed. From the graphical representation of the employment in the industrial sector, we can assume that the two factors drove employment in opposite directions and hence, especially for the period 1985 to the beginning of 2000s the range of employment change was relatively marginal (2.4-2.8 millions). Overall, the increasing trend matches the trend of the output of the industrial sector and the electricity consumed.

Figure 1: Electricity consumption (cons), Employment ( $n$ ), Electricity prices (p) and Real output (y) of the South African industrial sector (1970-2007)

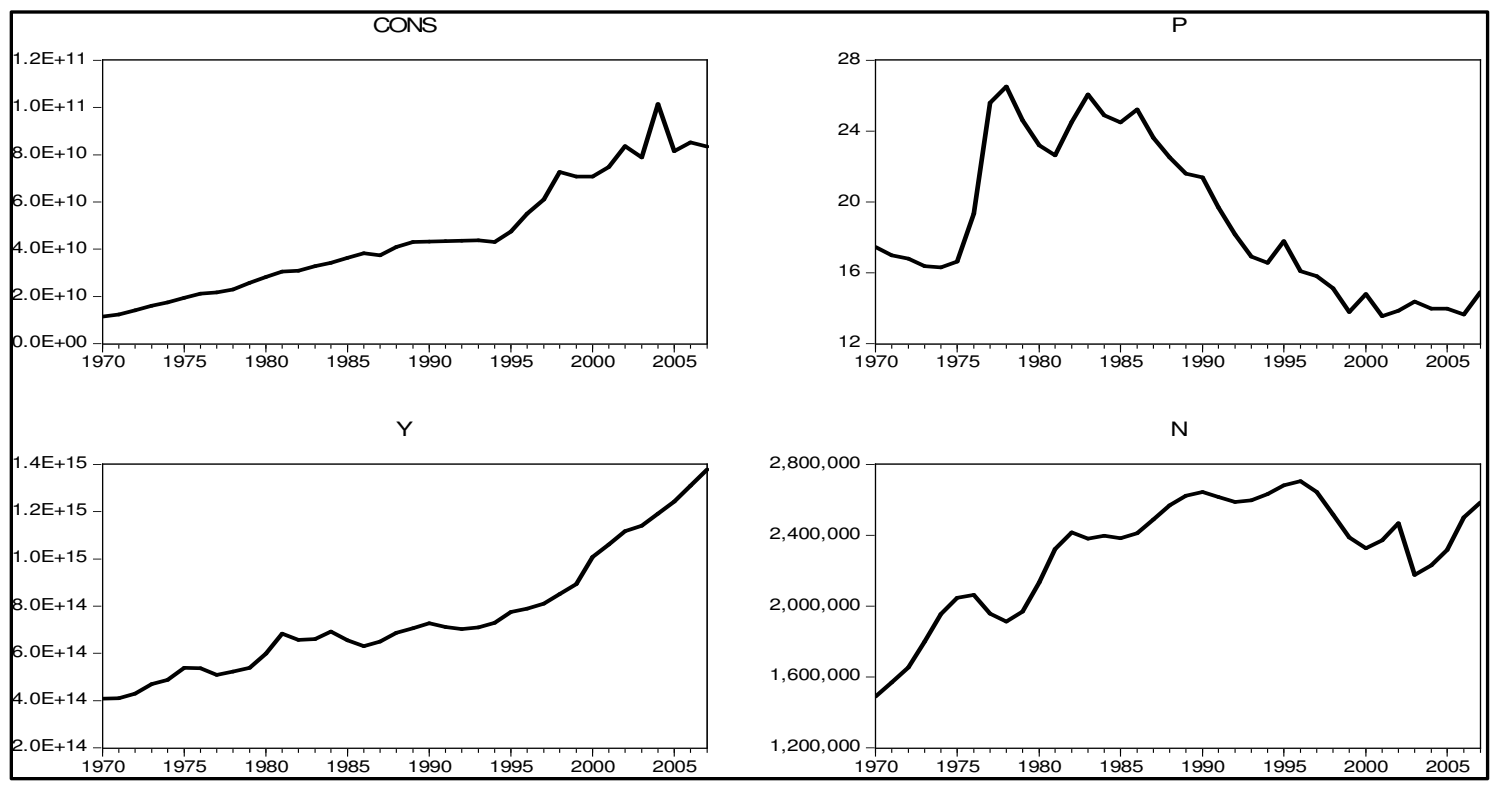

[Source: DoE (various issues), DoE (2009), Quantec databases (n.d.)] 
On the other side, the electricity prices increased drastically during the first half of the 1970 s, reaching a peak in the beginning of the 1980s. However, they started declining rapidly from the 1980s until the 2000s. Looking at the steep increase in prices from 1975 to 1976, we decided to proceed with an estimation leaving out the first five years of the sample and only start from 1976. Also, there is data available for most of the variables until 2010-2011, however information on sectoral electricity consumption from the Energy Balances was released lastly for 2009 and for prices for 2008/09. Usually, latest reports for energy data are re-evaluated as soon as more information becomes available and hence, 2007 was the latest most accurate year of energy data. Also, after $2008 / 09$, the international crisis has affected the output of the economy and so, the decision was to leave the years after 2008 outside the estimated sample. In the future when information becomes available for the years after the crisis, this period can be treated as a structural break in any economic analysis of data.

From Figure 1, it can also be observed that overall real output and employment have had a constant positive correlation with the electricity consumption; while prices' variation is more intense through the years and might show a more changeable relationship with electricity consumption on an annual basis. These observations might be an indication on the a priori expectations of the Hansen test results. 


\section{Empirical results}

As discussed in the methodology section, before proceeding with the estimation using the Kalman filter, the Hansen test is performed to confirm or reject the parameter instability. From the graphical representation of the data, a more stable coefficient is expected for output and employment while the relationship between price and consumption of electricity is expected to be varying over the years, represented in an unstable parameter. The null hypothesis of the Hansen test is parameter stability and an Lc statistic is used (Lagrange Multiplier tests family). If even one of the coefficients is confirmed statistically to be unstable, then the Kalman filter will produce better results than a least squares estimation.

Table 3: Hansen test results for parameter stability

\begin{tabular}{lccc}
\hline & Lc statistic & p-value & Conclusion \\
\hline Iy, In & 0.192 & $>0.2$ & $\begin{array}{c}\text { The null hypothesis }\left(\mathrm{H}_{0} \text { : parameter stability) cannot be rejected } \rightarrow\right. \\
\text { the parameters are constant }\end{array}$ \\
Ip & 0.400 & 0.077 & $\begin{array}{c}\text { The null hypothesis }\left(\mathrm{H}_{0} \text { : parameter stability) can be rejected } \rightarrow\right. \\
\text { the parameter is not constant }\end{array}$ \\
\hline
\end{tabular}

Table 3 presents the results of the Hansen test. The test statistic for output and employment is 0.192 with $p$-value higher than 0.2. Because the p-value is bigger than the $10 \%$ level of significance, the null hypothesis of parameter stability cannot be rejected and hence, the parameters for output and employment are found to be constant. The second row shows that results of the Hansen test for the price coefficient. The test statistic is 0.4 and its p-value is 0.077 . Since the $p$-value is smaller than the $10 \%$ level of significance, the null hypothesis of the test can be rejected. Hence, the conclusion is that the price coefficient is not constant through the years. All in all, based on the Hansen test results, in the Kalman filter estimation we should consider the coefficients for output and output as constant while the one for price as time-varying.

Table 4 reports the Kalman filter estimation results. $C(1)$ and $c(2)$ (constant coefficients) show the output and employment coefficients respectively, while $c(3)$ is the constant parameter of the equation They are both positive and statistically significant: any positive change in the output or employment will result in an increase of the electricity consumption.

Table 4: Kalman filter estimation results

\begin{tabular}{lcc}
\hline Space model & Sample & $1976-2007$ \\
& Included observations & 32 \\
& Number of iterations to convergence & 9 \\
\hline & & \\
Variables & Estimated coefficients & -values \\
c(1) (output coefficient) & 0.690 & 0.000 \\
c(2) (employment coefficient) & 0.252 & 0.061 \\
c(3) & -4.065 & 0.000 \\
\hline & Final state & p-values \\
sv1 (price coefficient) & -0.952 & 0.000 \\
\hline
\end{tabular}




\begin{tabular}{cc}
\hline Goodness of fit & 8.502 \\
Log likelihood & -0.344 \\
Akaike info criterion & -0.206 \\
Schwarz criterion & -0.298 \\
Hannan-Quinn criterion & \\
\hline
\end{tabular}

Sv1 is the average of the price elasticity over the years 1976 to 2007 and it is negative as expected (Law of demand: the higher the price of a good, the lower the quantity consumed of the good). Overall it is statistically significant with a p-value of zero. Both output and price coefficients are very close to the average coefficients reported in Inglesi-Lotz and Blignaut (2011) for the industrial sector. The price coefficient for the examined period 1993 to 2006 was -0.869 (here, 0.952 ) and the output elasticity was 0.712 (here, 0.690).

Figure 2: Estimated Price elasticity from 1976 to 2007

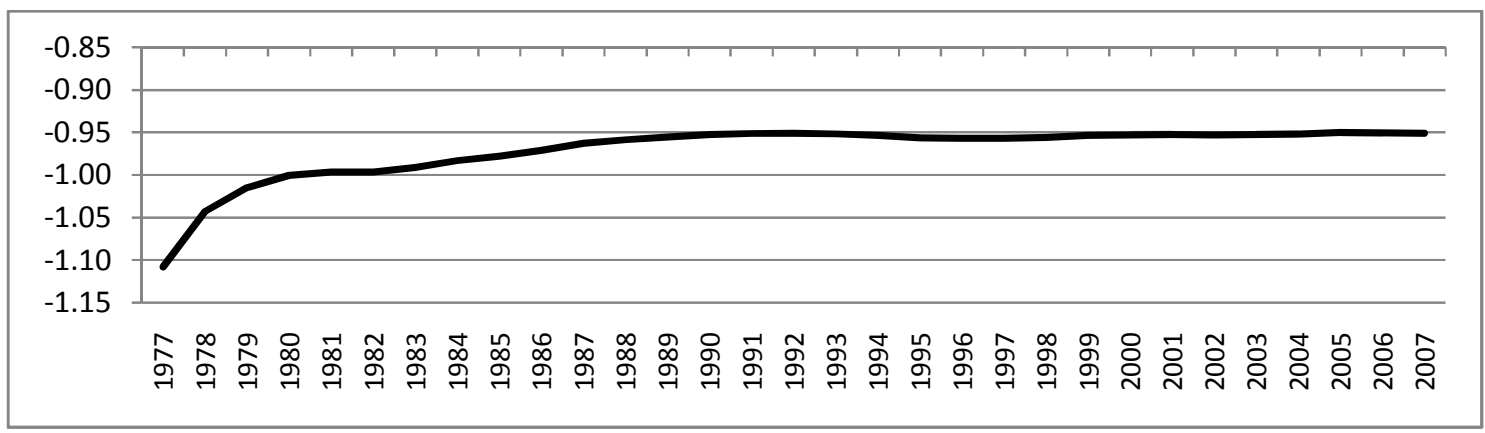

Figure 2 illustrates the evolution of the price elasticity. In the beginning of 1980s, the price elasticity of electricity demand was close to unit elastic. Since then, it has decreased in absolute values from -1 in 1980 to -0.953 in 1990 . Since then, the elasticity stabilised around -0.95 showing that the industrial sector has experienced an inelastic demand. In other words, the behaviour of the industrial consumers did not vary significantly in the 2000s. That might be an explanation why in some studies, researchers do not assume that price has played a significant role in the fluctuations of electricity consumption in the industrial sector and hence, prices were not included in the estimations (Ziramba, 2009). 
Figure 3: Electricity prices and estimated price elasticity for the industrial sector 1977-2007

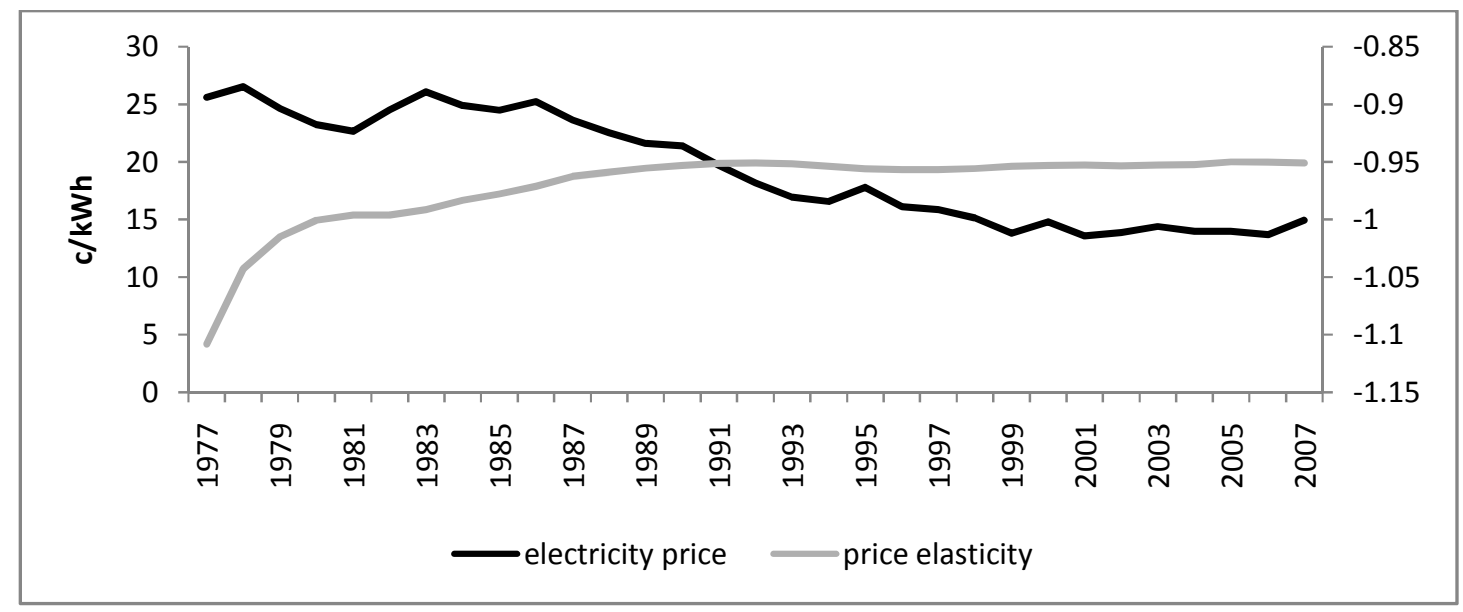

This result also confirms the main conclusion of the Inglesi-Lotz (2011) paper on aggregate electricity consumption: sensitivity of consumers to price fluctuations becomes smaller in absolute terms while the real prices of electricity declined over the last half of the sample examined. It can be seen in Figure 3 that from 1977 until the beginning of 1990s, the electricity prices decreased in real terms and the price elasticity became lower in absolute terms. However, from the 1990s until the end of the sample the prices got stabilised at much lower rates than those of the 1970s and 1980s and hence, the sensitivity of the consumers did not change drastically. 


\section{Conclusion}

Being the main electricity user, the industrial sector of South African plays an important role in the path of electricity consumption. Knowing and understanding the behaviour of the sector with regards to electricity consumption will assist policy makers implement appropriate policies. The sector's electricity performance has attracted attention recently. Ziramba (2009) studied the energy consumption of the industrial sector in South Africa and its interaction with other variables such as industrial output and employment (but not electricity prices). Later, Inglesi-Lotz and Blignaut (2011) using panel data techniques, found out that among various economic sectors, the industrial sector's electricity consumption was found sensitive to price and output fluctuations on average during the period 1993 to 2006.

Although most of studies assume that the price elasticity of electricity demand remains constant through the years that is industrial consumers behave the same way to price fluctuations regardless the economy's conditions or the actual level of prices. In South Africa, the electricity prices were kept low for a long period of time making the economy as a whole being not reactive to price changes (Inglesi-Lotz, 2011). In this paper, following Inglesi-Lotz(2011) that did it for the economy-wide electricity consumption, the Kalman filter methodology was used to allow the price elasticity of industrial electricity demand be time-varying. To capture other factors affecting electricity consumption, real output and employment are also included in the specification.

The findings of the exercise show that indeed price sensitivity changed since the 1970s: it has decreased in absolute values from -1 in 1980 to -0.953 in 1990 . Since then, the elasticity stabilised around -0.95 showing that the industrial sector has experienced an inelastic demand. In other words, the behaviour of the industrial consumers did not vary significantly in the 2000s. This result also confirms the main conclusion of the Inglesi-Lotz (2011) paper on aggregate electricity consumption: sensitivity of consumers to price fluctuations becomes smaller in absolute terms while the real prices of electricity declined over the last half of the sample examined.

These results also allow us to speculate on the effect of further electricity price increases planned by Eskom and NERSA for the next years. One must not expect an immediate change in the industrial sector's behaviour with the increase of prices. However, in the long run and as the prices increase, probably reaching the levels of the 1970s or even before, the industrial sector's behaviour might change and the elasticity might end up at levels higher than one (elastic).

Although, the price elasticity of electricity consumption is high, the historically low level of electricity prices was a factor for the unchanged sensitivity of the industrial sector in the last decade. This low level of prices is an indication that made the electricity costs of the economy to contribute little in the total cost of operation of all the economic sectors. However, as can be seen in InglesiLotz and Blignaut (2011a) in many industrial sub-sectors, the percentage of electricity costs to total for 2005 has not exceeded 3\% showing that electricity is not an unimportant input to the total costs of business. 


\section{References}

Abdelaziz, E.A., Saidur, R., and Mekhilef, S. (2011). A review of energy saving strategies in industrial sector. Renewable and Sustainable Energy Reviews. Vol. 15, p 150-168.

Agnolucci, P. (2007). Non-transport energy consumption in the UK: a comparison of alternative approaches, mimeo. Cambridge: University of Cambridge.

Agnolucci, P. (2009). The energy demand in the British and German industrial sectors: Heterogeneity and common factors. Energy Economics. Vol. 31, p 175-187.

Al-Ghandoor, A., Al-Hinti, I., and Sawalha, S.A. (2008). Electricity consumption and associated GHG emissions of the Jordanian industrial sector: empirical analysis and future projection. Energy Policy. Vol. 36, p 258-267.

Amusa,H., Amusa, K., and Mabugu, R. (2009). Aggregate demand for electricity in South Africa: an analysis using the bounds testing approach to cointegration. Energy Policy. Vol. 37, p 4167-4175.

Beenstock, M., Goldin, E., and Nabot, D. (1999). The demand for electricity in Israel. Energy Economics. Vol. 21, p 168-183.

Caloghirou, Y.D., Mourelatos, A.G., and Thompson, H. (1997). Industrial energy substitution during the 1980s in the Greek economy. Energy economics. Vol. 19, 476-491.

Cuthbertson, K., Hall, S., Taylor, M.P. (1992). Applied Econometric Techniques. Harvester Wheatsheaf, New York, USA.

Department of Minerals and Energy, (DoE). (2009). Energy Price Report 2009. Department of Energy (DoE), Pretoria, South Africa.

Department of Minerals and Energy, (DoE). (Various issues). Aggregate energy balances. Department of Energy (DoE), Pretoria, South Africa.

Dilaver, Z., Hunt, L.C. (2010). Industrial electricity demand for Turkey: a structural time series analysis. Energy Economics. Vol. 33, p 426-436.

Dimitropoulos, J. , Hunt, L.C., Judge, G. (2005).Estimating underlying energy demand trends using UK annual data. Applied Economic letters. Vol. 12, p 239-244.

Enevoldsen, M.K., Ryelund, A.V., and Andersen, M.S. (2007). Decoupling of industrial energy consumption and $\mathrm{CO} 2$ emissions in energy intensive industries in Scandinavia. Energy Economics. Vol. 29, p 665-692.

Engle, R.F., Granger, C.W.J. (1987). Co-integration and error correction: representation estimation and testing. Econometrica. Vol. 55, p 251-267.

Greening, L.A., Boyd, G., Roop, J.M. (2007). Modeling of industrial energy consumption: An introduction and context. Energy Economics. Vol. 29, p 599-608.

Hansen, B.E. (1992). Tests for parameter instability in regressions with I(1) processes. Journal of Business and Economic Statistics. Vol. 10, p 321-335.

He, Y.X., Yang, L.F., He, H.Y., Luo, T., and Wang, Y.J. (2011). Electricity demand price elasticity in China based on computable general equilibrium model analysis. Energy. Vol. 36, p 1115-1123.

Hendry, D., Juselius, K. (2000). Explaining cointegration analysis: part I. Energy Journal. Vol. 21, p 142.

Hendry, D., Juselius, K., (2001). Explaining cointegration analysis: part II. Energy Journal. Vol. 22, p 75-120. 
Hunt, L.C., Judge, G., and Ninomiya, Y. (2003). Underlying trends and seasonality in UK energy demand: a sectoral analysis. Energy Economics. Vol. 25, p 93-118.

Inglesi, R., (2010). Aggregate electricity demand in South Africa: conditional forecasts to 2030. Applied Energy. Vol. 87, p 197-204.

Inglesi-Lotz, R. (2011). The evolution of price elasticity of electricity demand in South Africa: A Kalman filter application. Energy Policy. Vol. 39, p 3690-3696.

Inglesi-Lotz, R. and Blignaut, J.N. (2011a). Estimating the price elasticity of demand for electricity by sector in South Africa. South African Journal of Economic and Management Sciences. Vol.14, p 449465.

Inglesi-Lotz, R. and Blignaut, J.N. (2011b). South Africa's electricity consumption: A sectoral decomposition analysis. Applied Energy. Vol. 88, p 4779-4784.

Jamil, F. and Ahmad, E. (2011). Income and price elasticities of electricity demand: Aggregate and sector-wise analyses. Energy Policy. Vol. 39, p 5519-5527.

Johansen, S. (1991). Estimation and hypothesis testing of cointegration vectors in gaussian vector autoregressive models. Econometrica. Vol. 59, p 1551-1580.

Kamerschen, D.R. and Porter, D.V. (2004). The demand for residential, industrial and total electricity, 1973-1998. Energy Economics. Vol. 26, p 87-100.

Lynk, E.L. (1989). The demand for energy by UK manufacturing industry. Manchester School of Economic and Social studies. Vol. 57, p 1-16.

Morisson, G.W., Pike, D.H. (1977). Kalman filter applied to statistical forecasting. Management Science. Vol. 23, p 768-774.

Nakajima, T., Hamori, S. (2010). Change in consumer sensitivity to electricity prices in response to retail deregulation: a panel empirical analysis of the residential demand for electricity in the United States. Energy Policy. Vol. 38, p 2470-2476.

National Energy Council (NEC). (1990). South African Energy Statistics 1950-1989. National Energy Council, Pretoria, South Africa.

Odhiambo, N.M. (2009). Electricity consumption and economic growth in South Africa: A trivariate causality test. Energy Economics. Vol. 31, p 635-640.

Pindcyck, R. (1979). Interfuel Substitution and the Industrial Demand for Energy: An International Comparison. Review of Economics \& Statistics. Vol. 61, p 169-179.

Quantec (n.d.) Quantec databases. Pretoria, South Africa.

Roy, J., Sanstad, A.H., Sathaye, J.A. and Khadariia, R. Substitution and price elasticity estimates using inter pooled data in a translog cost model. Energy economics. Vol. 28, p 706-719.

Slade, M.E. (1989). Modelling stochastic and cyclical components of technical change: an application of the Kalman filter. Journal of Econometrics. Vol. 41, p 363-383.

Ziramba, E. (2009). Disaggregate energy consumption and industrial production in South Africa. Energy Policy. Vol. 37, p 2214-2220. 